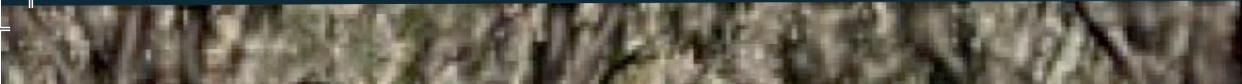

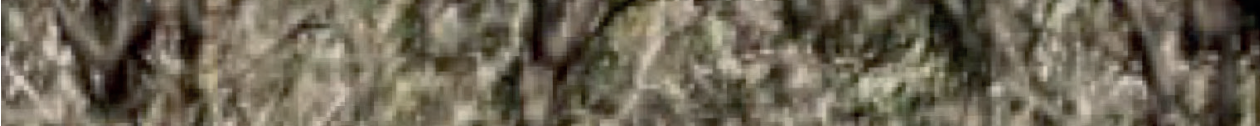

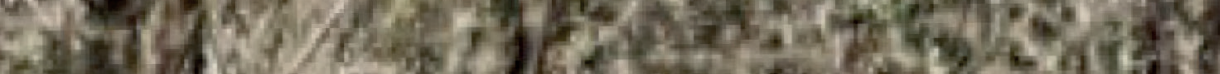

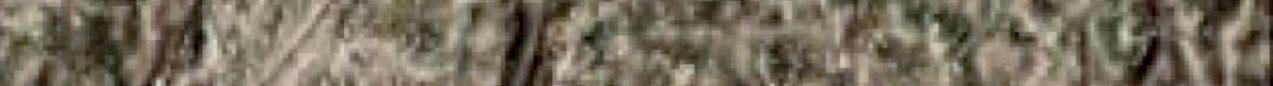

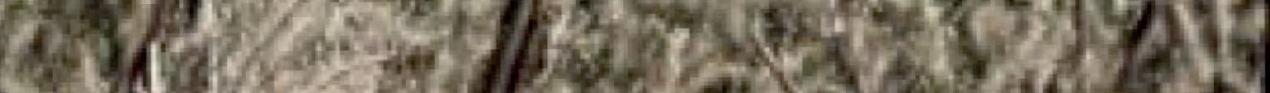
Whing

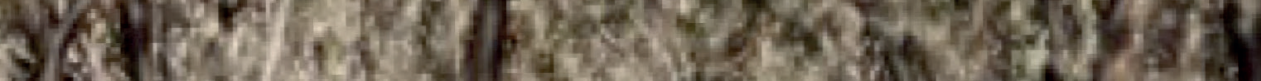
Yos She Af

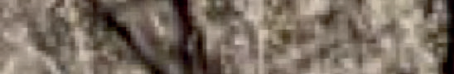
Nation.

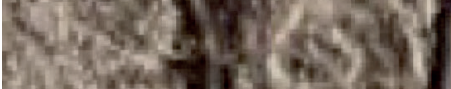

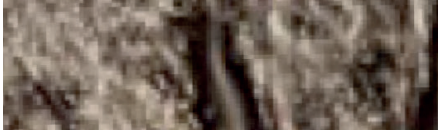
thy M.

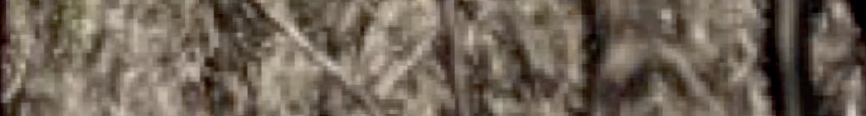

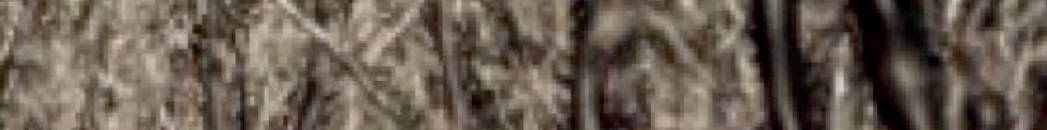

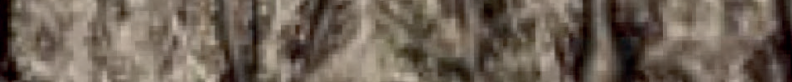
ofingly pistis (2). 19

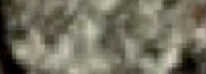
Dimatifing Cistif fingtistis

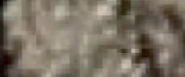

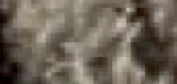
$x^{2}+2 y$

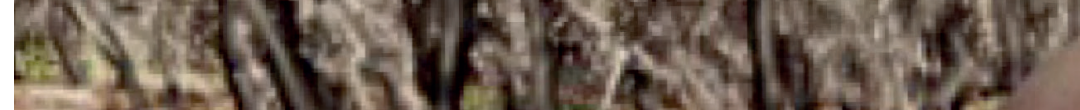

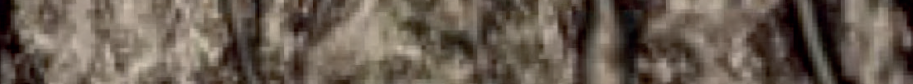

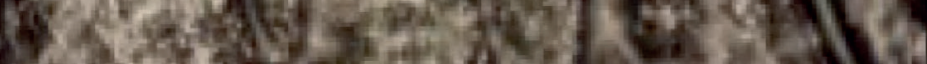

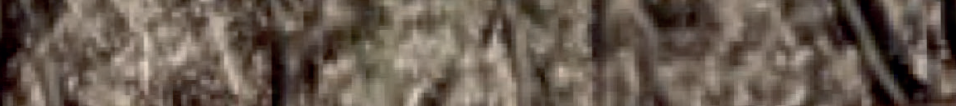

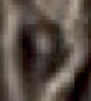
sersul

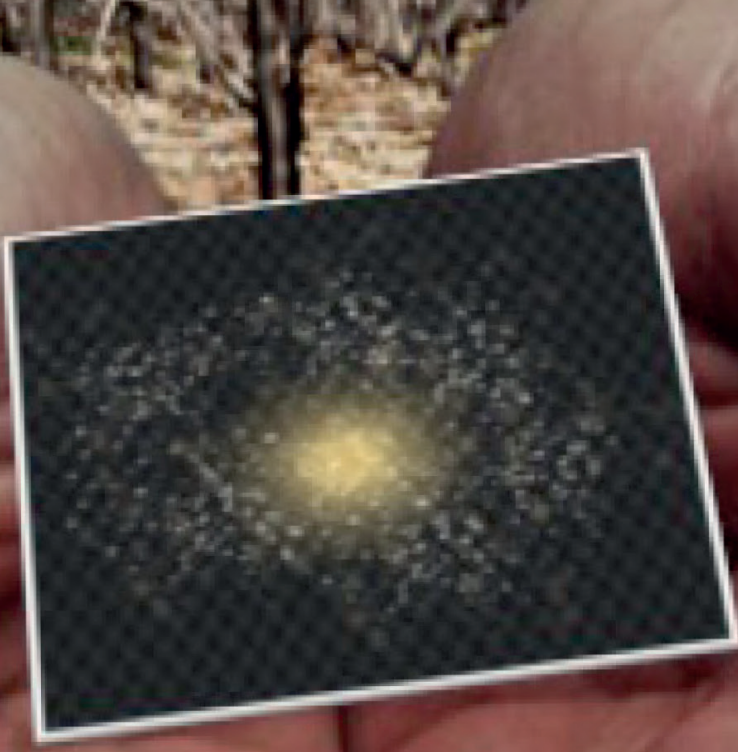

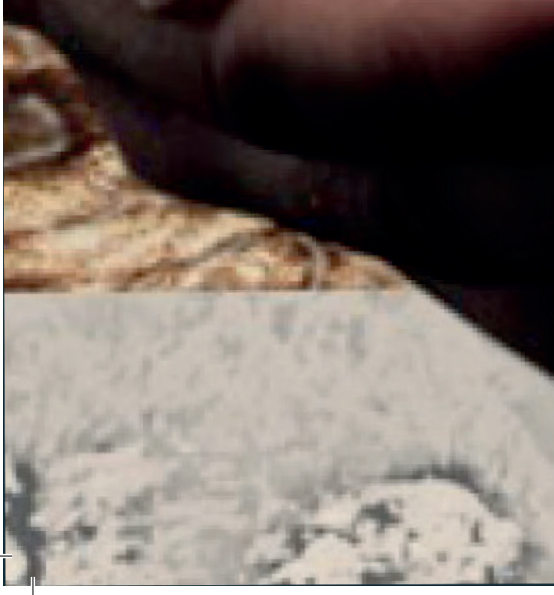

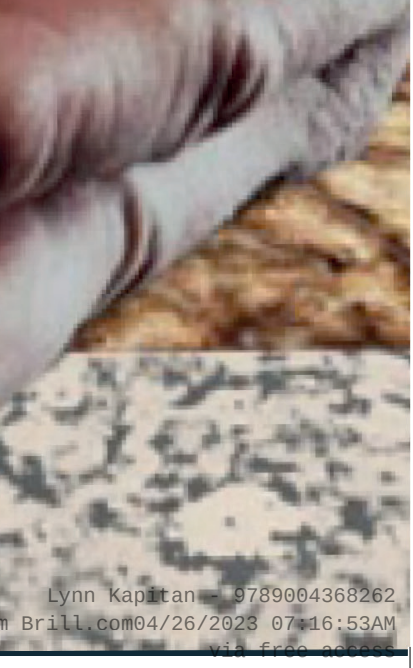




\section{EPILOGUE: A LETTER TO ART THERAPISTS OF THE FUTURE}

\section{Lynn Kapitan}

You probably don't remember me, but I have always dreamed of you. You carry my deep desire that art therapists are thriving in communities the world over, like the spark of many campfires along the shore on a dark and starry night. I see you gathering in the borderlands, the overlaps and intersections of art therapy's many different histories. Connected by the vast river of human knowledge, you are re-claiming its eddies, flotsam, and safe landings. You move with ease, your work valued and practiced in countless diverse communities - but it was not always so. Toss another log on the fire and I will share the visions I've had of you, glimpsed from many years of journeying.

I am an art therapist of what I think of as the second generation, taught by the art therapy "pioneers" - that small but feisty band, mostly in the USA and UK, who named and defined art therapy, and then announced its birth. I honoured them as elders and mentors, and told their stories of having discovered a whole new field. Their times were tumultuous: living through the Cold War, the USA Civil Rights Movement, and the Vietnam War, when institutions that once had seemed so solid began to crack from all the clamouring for freedom and change. Art therapy, they said, arose from a search for common ground in a world no longer unified in belief.

Trailblazers, they were. Their pioneer legacy gave my generation - and indeed all art therapists to come - a path forward, bushwhacked through dense thickets of bias that so often kept art therapy from being taken seriously. They sojourned with psychoanalysts, Jungians, social scientists, modernist painters, and art diagnosticians. If, like me, you had been an art therapist back then, you'd have studied the "art of madness" from psychiatrists and learned to analyse drawings for graphic signs of schizophrenia, personality disorders, abuse, addiction, and suicidal ideation. You'd have created scribble drawings, bridge drawings, family drawings, and human figure drawings, and then moved on to create mandalas, yes, and later still

Opposite: Figure 1 Detail of Dreaming Australia, into art therapy's future. Lynn Kapitan (2018). Digital collage.

(C) KONINKLIJKE BRILL NV, LEIDEN, 2019 | DOI:10.1163/9789004368262_016 
to retreat from the clinic entirely. Seeking validation, you might have been persuaded by the idea that art therapists were a modern resurrection of long-lost shamans - buying into a mainstream mythology that shamanism is an ancient archetype rather than a living cultural reality for Indigenous peoples (Napoli, 2018). It must seem unbelievable to you now; even for me it is painful to look only a short distance back and see my own inability to recognise these harmful views.

In my times, enormous energy was needed to keep the spark of art therapy alive within those well defined, clearly named, legally protected, and scientifically sanctioned structures known as a profession. I learned to see with disciplinary filters, to appraise new knowledge in relationship to sanctioned knowledge, new people or practices relative to established practices (Kapitan, 2015). I put aside my crafty, sensuous, howling ways of making art - that is, of making life, as so many women do - in exchange for access and for the science that would enhance art therapy's worth. The reflective dimension that made us empathically human felt as though it might slip away. As new priorities and complex needs competed for attention, my profession became vulnerable to fracture. In the constant struggle to gain a valid foothold in the patriarchal commerce of healing, somewhere in me I knew that something was not right with this configuration of things.

When I imagine you, future art therapists, I see you practicing in the vast fullness of human knowledge, freely shared like smooth pebbles released into the river's constantly moving flow. In your time you no longer have to choose whether to claim legitimacy by embracing science or to claim authenticity by embracing art. Art is expansively defined and practiced as an integral part of living, what people simply do to connect, to participate, and to share their lives with others. Freed from the false binaries of art and therapy, I envision you forever creating new approaches based on where and with whom you practice. You are skilled in "third space thinking" that attends to reciprocity and exchange, of the hybrid and the transcultural. If my generation's old identity question was "who are we?" I imagine yours will be "how do we all find home in this interconnected world?"

Art therapists of the future, more than anything, I see you living the truth that diversity is essential to your communities' survival, and not simply because different voices are present. To take up the daunting challenges you face, a multitude of talents and perspectives are plainly needed. You would find it unacceptably limiting to believe that biology determines health or that art always transcends culture. Quite the contrary you understand that "transcending" culture is neither possible nor valuable; rather, art illuminates and communicates culture. Your experience affirms that people understand and express their distress in vastly diverse, culturally particular terms - as selves inseparable from their environments or kinship bonds, often intertwined with unsayable stories and the permeable spirit world (Watters, 2011).

Opposite: Figure 2 Detail of Morialta Conservation Park, South Australia. Eddee Daniel (2015). Photograph. 
But it was not always so. Your profession was named in the West, in centres of influence that exerted an inescapable gravitational pull. Then, with the forces of globalisation and technology, art therapy began to travel from the centre to the periphery. Global migration followed pathways worn deep from the carriage wheels, military boots, and shipping lanes of earlier colonising conquests, although this was barely noticed by most of us at first. Taking itself to be normal, superior and good, the West had long painted the Other as people without civilisation, without history, proper laws, or a proper God (Grosfoguel, 2011) - and later, in need of science and modern medicine to save them. I joined and help grow an art therapy field that had bought into this narrative - that art as healing was a new discovery rather than a practice as old as humankind. I wish that I, and others of my times, had seen through these violent myths from the beginning.

When did a critical mass of art therapists finally realise that the worldview of this profession had been too white and too Western for too long, excluding other colours and voices from mattering? I cannot say. But I remember well my own blinkered complicity. We lived and worked within a world-system that stigmatised, marginalised, and oppressed; I, and so many other art therapists, could not always recognise how the lives and fates of all people were affected by our own. Art would bring order out of chaos, or so I was taught. But I see now how this belief was marked by the colonising past and present. Throughout history those who bring "order" to others always presume to know it best (Biko, 1978). 
I imagine you, art therapists of the future, telling the stories of how the old colonising hierarchies of domination were interrupted, the creed of conquest and territory finally transformed. How you never had to buy into the idea of the DSM as a field guide to the whole world's illness and suffering (Watters, 2011) or take biomedical explanations as scientific fact. Gone are the whispers of supremacy that once nestled in the question of how best to heal a community's brokenness and despair. You heeded the call to transgress, aware of your capacity to either liberate or oppress. You have let go of taking responsibility for healing others and believe, instead, in a difference-centered responsibility. Each of you practices as a cultural being in dialogue with each other cultural being. Acutely aware that all are related to one another, no one is left behind and without full participation in their self-determination.

The world so very much needs the resilient communities you are committed to creating. Your artistry strengthens their social immune systems; your therapy is a collaborative partnership committed to healthy, free, and creative minds in a free, dynamic, and just social body (MartinBaro, 1994). You are rooted in local authority, far beyond the colonising drift of art therapy's past. Because the community - and not art therapy - is the central force of change, your power as an art therapist is elastic enough to shift and be transformed as well (Kapitan, 2015). In the openings of these spaces, you call forth multi-vocal, synchronic, mixed, and hybrid perspectives and visions for the work at hand. Disorienting complexity and ambivalence arise as well, and they are accepted as sources of creativity, energy, and transformation.

Future art therapists, I imagine you converting walls of fear into far-reaching corridors of creativity and exchange. Shaped by a living landscape of practice, you create entanglements with kindred others to generate new skills, identities, and knowledge that can only be found by journeying together. With ever more linkages, the greater are your widening circles of impact. Art therapy is shared from person to person, community to community, such that no one lays territorial claim to it. As a result thousands and thousands of people are benefitting from this vital resource. This, I believe, is what a re-claimative art therapy (Lawson, Wood and McKenna, this volume) must look like.

I am inspired by your commitment to break away from the too-narrow ledges and ways of the past to achieve the unfinished dream of de-colonisation. You have learned to reach out to those who do not share your same history and discovered how the perspective of each art therapist is relevant to that of every other. I close my eyes and listen to you tell your own hard-won stories of working within the margins and borderlands. I listen to the yarning (ibid): those of you with privileged identities telling of how you strayed from the dominant path, shed your old habits and lost your way, and heard the deep murmurings of the earth when you took finally root. And those of you with marginalised identities telling of how you held on tight against the force of strong currents, staying steadfast and true to your 


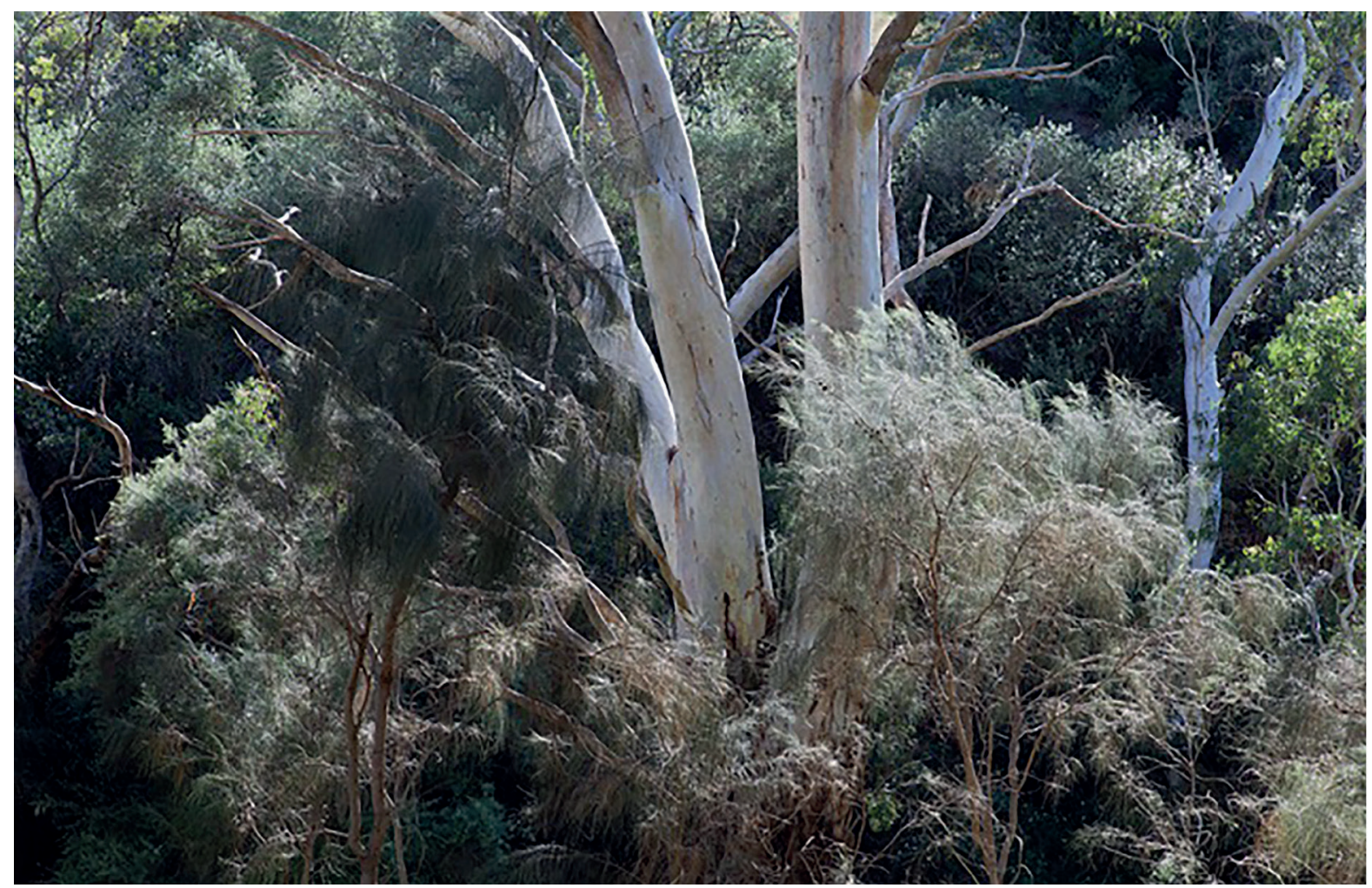

Figure 3 Morialta Conservation Park, South Australia. Eddee Daniel (2015). Photograph.

authentic ways of knowing. All of you sharing how, together in communities, you learned to think from your intimacy with all these places, to sit with the unnamed and follow its shadows (Akomolafe, 2016).

As I listen deeply with my heart, the ground beneath my feet shifts and cracks open. The colours of art therapy take on the reds and ochre of the Australian soil, the sage and sepias of the bush, and dusty charcoals of the campfires. "Where is here?" (Westwood, this volume) you ask. You are always asking this profound question, as it guides your knowing that the world is a web. My dreams are linked with you across time and space; our boundaries are porous and ever changing. We are in constant touch, thoroughly tangled up in each other's realities and histories. I imagine you theorising, hierarchising, interrogating, celebrating, deconstructing, and re-constructing your work as many others have before you. But what I love and celebrate most is how much further you are able to take art therapy - far more expansively and beyond anything I could ever conceive or even imagine. 


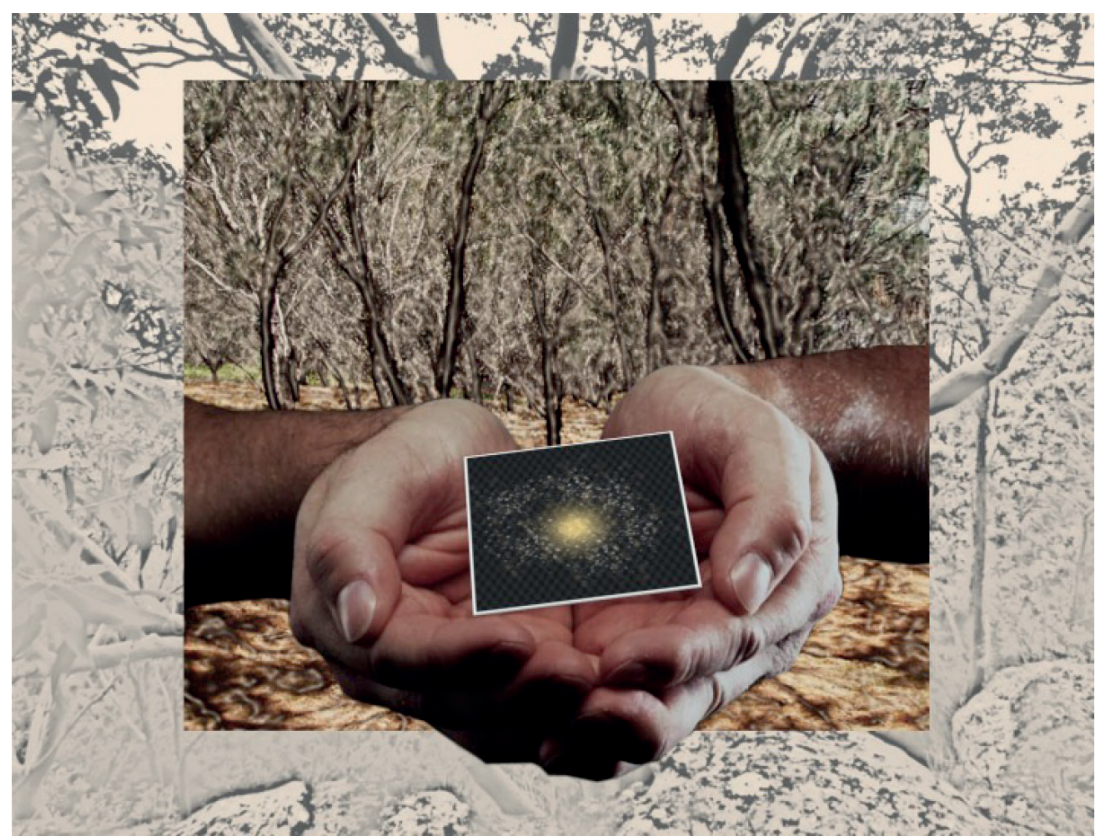

Figure 4 Dreaming Australia, into art therapy's future. Lynn Kapitan (2018). Digital collage.

I cup my hands reverently and imagine holding infinite images of you as the future of art therapy. But I do not think for a minute that when art therapy took its de-colonising, aesthetic turn, it was an easy embrace. Accountable to the 2,400 generations who were here before you, (Lawson et al, this volume) you would have had to help each other change the perceptual habits of so many art therapists in their lifetimes to be able to really see what is before your eyes (Henzell, this volume). What did you surround yourself with to say who you are? (Johnston, this volume). What myriad ways are you taking action on the knowledge that all oppression is interconnected? I dream of you heeding the call for liberation, courageously beginning the work of a different tomorrow.

Art therapists of the future, you inspire me by revealing what is possible. We cannot continue to live on this fragile earth without awareness of our interconnection to each other and to all beings. We must change. You carry my profound hope that thousands of years hence, though others may not know it, this work of healing will continue - in the movement of light and shadows across the landscape, in the rich and varied currents of creation ever flowing. 


\section{References}

Akomolafe, B. (2016, June 20). Dear white people - An open letter. Retrieved from https://upliftconnect.com/dear-white-people/.

Biko, S. (1978). I write what I like: Selected writings. Bowerdean Press, London, England.

Grosfoguel, R. (2011). Decolonising post-colonial studies and paradigms of political-economy: transmodernity, decolonial thinking, and global coloniality. Transmodernity: Journal of Peripheral Cultural Production of the Luso-Hispanic World, 1(1). Retrieved from https://escholarship.org/uc/item/21kbt3fq.

Henzell, J. (2019). Psyche nullius: Reflections on art psychotherapy and psychiatry down under. In: A. Gilroy, S. Linnell, T. McKenna, and J. Westwood (Eds.). Art therapy in Australia: Taking a postcolonial, aesthetic turn. Brill Sense, Leiden and Boston, MA.

Johnston, P. (2019). Talking you talking me talking Aborigine. In: A. Gilroy, S. Linnell, T. McKenna, and J. Westwood (Eds.). Art therapy in Australia: Taking a postcolonial, aesthetic turn. Brill Sense, Leiden and Boston MA.

Kapitan, L. (2015). Arts therapies in the ecotone: Contact, collaboration, and creative entanglement. Keynote address to the Joint Conference of the Australian and New Zealand Arts Therapy Association and the Australian Creative Arts Therapy Association, Adelaide, Australia. October 2015.

Lawson, C., Woods, C., and McKenna, T. (2019). Towards Indigenous Australian knowing. In: A. Gilroy, S. Linnell, T. McKenna, and J. Westwood (Eds.). Art therapy in Australia: Taking a postcolonial, aesthetic turn. Brill Sense, Leiden and Boston, MA.

Martín-Baró, I. (1994). Writings for a liberation psychology. Harvard University Press, Boston, MA.

Napoli, M. (2018). Ma tallepo 'opu ma 'akkala kennetto / We are waking up our story together: Arts-based Indigenous methodology. Unpublished doctoral dissertation. Mount Mary University, Milwaukee, WI.

Watters, E. (2011). Crazy like us: The globalisation of the American psyche. The Free Press, New York, NY.

Westwood, J. (2019). Hybrid creatures: Art therapy education in Australia. In: A. Gilroy, S. Linnell, T. McKenna, and J. Westwood (Eds.). Art therapy in Australia: Taking a postcolonial, aesthetic turn. Brill Sense, Leiden and Boston MA. 